\title{
時間遅れシステムに関連したある種のたたみ込み 積分作用素のスペクトルの数值計算についで*
}

平田健太郎 ${ }^{\dagger}$

\author{
On Numerical Computation of the Spectrum of a Class of \\ Convolution Operators Related to Delay Systems*
}

\section{Kentaro HiRATA ${ }^{\dagger}$}

\begin{abstract}
A class of convolution operators on fixed interval with initial values is considered. The numerical computation of its spectra is attempted via a finite-dimensional approximation so-called fast sampling and hold. In contrast to the case of matrices, the spectrum of an operator is not continuous against small perturbations in general. This implies that a fine approximation does not necessarily lead to better estimates close to the true values. Therefore, one must provide a mathematical justification of the procedure depending on the operator of interest. In this paper, continuity of the spectrum of the convolution operator described above is proved and a numerical computation formula for the calculation of its eigenvalues is given.
\end{abstract}

\section{1.はじめに}

関数解析における積分作用素の重要性はいうまでもな く，たとえば $[3,9]$ などの入門書においても，種々の積分 作用素について様々な角度から議論がなされている. 最 も基本的なものは, 2 変数関数 $K(s, t)$ を積分核とする以 下のようなタイプの作用素であり,

$$
y(s)=\int_{a}^{b} K(s, t) x(t) d t
$$

積分核の性質により, 連続核積分作用素や HilbertSchmidt 型積分作用素などに分類される。また，積分区 間の上端を $b$ から $s$ に変更した（あるいは $t>s$ のとき， $K(s, t)=0$ と制限した) Volterra作用素，さらに積分核 が変数間の差のみの関数 $K(s, t)=\rho(s-t)$ となるような たたみ込み積分作用素は, 線形系の時間応答や状態遷移 を表すことから，システム理論において重要な役割を果 たしており，そのノルムないしスペクトルはシステムの 安定性や性能の重要な尺度となっている。たとえば，核 関数 $g(t)$ に対する $\mathbf{L}^{2}[0, \infty]$ 上のたたみ込み積分の作用素 ノルムは $G(s)=\mathcal{L}[g]$ の $H^{\infty}$ ノルムにほかならない.ま

\footnotetext{
* 原稿受付 2007 年 6 月 25 日

†奈良先端科学技術大学院大学 情報科学研究科 Graduate School of Information Science, Nara Institute of Science and Technology; 8916-5 Takayama-cho, Ikoma, Nara 630-0192, JAPAN

Key Words: convolution operator, perturbation, spectrum.
}

た $\mathbf{L}^{2}[0, h]$ 上のたたみ込み積分の作用素ノルムはむだ時 間系の 1 ブロック $H^{\infty}$ 問題の最適值を与える $[14,10,11]$. さらに, サンプル值 $H^{\infty}$ 設計問題の可解性の必要条件も, これら作用素のノルム条件として記述される $[1,13,2]$.

一方，ある種の微分差分系や，遅延フィードバック制 御下にある状態にジャンプを有する線形システムの時間 発展も，類似の作用素によって記述されることが知られ ている $[5,4]$. これは, サンプル值制御系のリフティング 表現 $[13,1]$ 同様, 関数要素を状態変数にとることによっ て，系の動特性を無限次元の離散時間系として表現する ものである。いま $\mathcal{Z}:=\mathbf{R}^{n} \oplus\left\{\mathbf{L}^{2}[0, h]\right\}^{n}$ とし，適当なサ イズの行列 $A, B, P, R$ によって作用素 $\mathcal{F}: \mathcal{Z} \rightarrow \mathcal{Z}$ を

$$
\begin{aligned}
\mathcal{F}\left[\begin{array}{c}
z_{1} \\
z_{2}(\cdot)
\end{array}\right]= & {\left[\begin{array}{c}
P\left\{e^{A h} R z_{1}+\int_{0}^{h} e^{A(h-\xi)} B z_{2}(\xi) d \xi\right\} \\
e^{A \cdot} R z_{1}+\int_{0}^{\cdot} e^{A(\cdot-\xi)} B z_{2}(\xi) d \xi
\end{array}\right] } \\
=: & {\left[\begin{array}{ll}
\mathcal{F}_{11} & \mathcal{F}_{12} \\
\mathcal{F}_{21} & \mathcal{F}_{22}
\end{array}\right]\left[\begin{array}{c}
z_{1} \\
z_{2}(\cdot)
\end{array}\right] }
\end{aligned}
$$

のように定めよう。すると前述の系の状態遷移はこの初 期条件を伴った，たたみ込み積分作用素によって記述さ れる $[6,7]$. これらの系の安定性が作用素 $\mathcal{F}$ のスペクト ルによって特徴づけられるため，具体的にその分布を計 算したいという要求が生じる。本論文では $\mathcal{F}$ のスペクト ルの数值計算法について考える。

先行研究 $[4,5]$ では $\mathcal{F}$ がコンパクト作用素であり，そ の固有值がある超越方程式の根として与えられることが 
示されている。したがって，適当な初期值から繰り返し 型の非線形方程式の求解をおこなえば，原理的には固有 值を求めることができる。しかし実際上無限に局所探索 を繰り返さないためには，いかに真值の近傍の初期值を 与えるか，いかにして多点探索の初期值集合を同時的に 与えるかなどの問題がある。そこで作用素の出力を階段 関数近似し，スペクトルの計算を行列の固有值問題に帰 着させる。これはサンプル値制御理論における，いわゆ る “高速サンプル\&ホールド”と同様の手法である．離散 近似のサンプル周期が十分に短ければ，これらの計算法 によって精度のよい近似值が得られると想像されるが， 文献 [12]においてサンプル值系の周波数応答に関して示 されているように，理論的な裏づけは自明ではない。さ らに意外なことに，このような離散近似による数值計算 の妥当性については，それがしばしば実用上使用されて いるにもかかわらず，初期条件をもたない一般の積分作 用素に限っても，これまでまとまった形では必ずしも議 論されていないようである。本論文の目的は，作用素 $\mathcal{F}$ のスペクトル計算を行列の固有值問題に帰着させる方法 について，その数学的裏づけを可能な限り直接的に与え ることである。

\section{2. 数学的準備}

本節では，主結果を導出するための数学的準備として， 必要となる定理を列挙する。空間 $X$ から $Y$ へのすべて の有界作用素の集合を $\mathcal{B}(X, Y)$ で，すべての閉作用素の 集合を $\mathcal{C}(X, Y)$ で表すものとし，簡単のため $\mathcal{B}(X, X)$ お よび $\mathcal{C}(X, X)$ をそれぞれ $\mathcal{B}(X), \mathcal{C}(X)$ と表記する。また 作用素 $\mathcal{T}$ のスペクトルを $\Sigma(\mathcal{T})$ で表す.

【定理 1】([3], p.342) 作用素 $\mathcal{T} \in \mathcal{B}(X)$ がコンパクト であるとき， $\Sigma(\mathcal{T})$ の 0 と異なる部分は，たかだか可算 個の点からなる：

$$
\Sigma(\mathcal{T}) \cap\{s \in \mathbf{C} \mid s \neq 0\}=\left\{s_{k}\right\}
$$

$\left\{s_{k}\right\}$ が可算無限の場合は $\lim _{k \rightarrow \infty} s_{k}=0$ である. 各 $s_{k}$ はT $\mathcal{T}$ 固有值で，その多重度は有限である。

したがって，半径 $\gamma>0$ の円 $D$ によって $\Sigma(\mathcal{F})$ を分割し， $D$ 外部の $\mathcal{F}$ の固有值を選べば，文献 [8]（p.181）の意味 での有限固有值系 $\Sigma^{\prime}(\mathcal{F})$ を得ることができる。

【定理 2】([8], IV-§3.5) 作用素 $\mathcal{T} \in \mathcal{C}(X)$ の固有值の うち，有限固有值系からなる $\Sigma(\mathcal{T})$ の部分は， $\mathcal{T}$ に対す る generalized sense，あるいはギャップ距離の意味での 摂動に対して連続である。

【定理 3】 ([8], p.206) いま $\mathcal{T}, \mathcal{T}_{n} \in \mathcal{C}(X), n=1,2, \ldots$ とする。 $\mathcal{T} \in \mathcal{B}(X)$ であるとき, generalized sense にお いて $\mathcal{T}_{n} \rightarrow \mathcal{T}$ であるための必要十分条件は，十分大きな $n$ に対して $\mathcal{T}_{n} \in \mathcal{B}(X)$ かつ $\left\|\mathcal{T}_{n}-\mathcal{T}\right\| \rightarrow 0$ となることで ある。

定理 2 で述べている連続性をより詳細にいうならば 以下のとおりである $([8], \mathrm{p} .213)$. 有限固有值系 $\Sigma^{\prime}(\mathcal{T})$
が閉曲線 $\Gamma$ によって, $\Sigma(\mathcal{T})$ の残りの部分 $\Sigma^{\prime \prime}(\mathcal{T})$ と 分離されているとき, これに対応して空間 $X$ は $X=$ $M^{\prime}(\mathcal{T}) \oplus M^{\prime \prime}(\mathcal{T})$ と分解される. 固有值系 $\Sigma^{\prime}(\mathcal{T})$ の多重 度の総和を $m$ とすると, $\operatorname{dim} M^{\prime}(\mathcal{T})=m<\infty$ である. いま generalized sense において $\mathcal{T}_{n} \rightarrow \mathcal{T}$ であるとする。 このとき $\Sigma\left(\mathcal{T}_{n}\right)$ もまた $\Sigma^{\prime}\left(\mathcal{T}_{n}\right)$ と $\Sigma^{\prime \prime}\left(\mathcal{T}_{n}\right)$ に分離され， これに対応して空間 $X$ は $X=M^{\prime}\left(\mathcal{T}_{n}\right) \oplus M^{\prime \prime}\left(\mathcal{T}_{n}\right)$ と分 解されるが, $n$ が十分大きいとき, $M^{\prime}\left(\mathcal{T}_{n}\right), M^{\prime \prime}\left(\mathcal{T}_{n}\right)$ は それぞれ $M^{\prime}(\mathcal{T}), M^{\prime \prime}(\mathcal{T})$ に同型である (文献 [8], 定理 3.16). とくに, $\Gamma$ 内の $\Sigma\left(\mathcal{T}_{n}\right)$ の部分が, 多重度の総和が $m$ であるような有限固有值系に対応し, $\operatorname{dim} M^{\prime}\left(\mathcal{T}_{n}\right)=m$ である。

いま $\Sigma^{\prime}(\mathcal{T})$ を $\Sigma^{\prime}(\mathcal{T})$ 内のいずれかひとつの固有值に 置き換えても同じことがいえるので, generalized sense における微小な摂動に対して, 閉作用素 $\mathcal{T}$ の有限固有值 系の各固有值の変化は微小である.

\section{3. 主結果}

ヒルベルト空間 $\mathcal{Z}$ の要素 $z=\left[\begin{array}{ll}z_{1}^{*} & z_{2}^{*}(\cdot)\end{array}\right]^{*}$ に対するノ ルムは以下のように与えられている。

$$
\|z\|_{\mathcal{Z}}^{2}=\left\|z_{1}\right\|^{2}+\left\|z_{2}(\cdot)\right\|_{\left\{\mathbf{L}^{2}[0, h]\right\}^{n}}^{2}
$$

以下では簡単のため, $\left\{\mathbf{L}^{2}[0, h]\right\}^{n}$ を $\mathbf{L}^{2}[0, h]$ と略記する. いま,

$$
\begin{aligned}
\phi_{z} & :=\left[\begin{array}{ll}
\mathcal{F}_{21} & \mathcal{F}_{22}
\end{array}\right] z \\
U & :=\left\{z \mid z \in \mathcal{Z},\|z\|_{\mathcal{Z}}=1\right\}
\end{aligned}
$$

とする。

\section{【補題 1】}

(a) ある定数 $K$ が存在して, 任意の $z \in U$ と任意の $\theta \in[0, h]$ に対して

$$
\left\|\phi_{z}(\theta)\right\| \leq K
$$

を満たす。

(b) 任意の $\epsilon>0$ が与えられたとき, ある $\delta>0$ が存在 して，任意の $z \in U$ と， $\left|\theta_{1}-\theta_{2}\right|<\delta$ であるような 任意の $\theta_{1}, \theta_{2} \in[0, h]$ に対して,

$$
\left\|\phi_{z}\left(\theta_{2}\right)-\phi_{z}\left(\theta_{1}\right)\right\| \leq \epsilon
$$

を満たす。

（証明）（a）いま，

$$
\begin{aligned}
\left\|\phi_{z}(\theta)\right\| & =\left\|e^{A \theta} R z_{1}+\int_{0}^{\theta} e^{A(\theta-\xi)} B z_{2}(\xi) d \xi\right\| \\
& \leq\left\|e^{A \theta} R z_{1}\right\|+\left\|\int_{0}^{\theta} e^{A(\theta-\xi)} B z_{2}(\xi) d \xi\right\|
\end{aligned}
$$

である. 行列の誘導ノルムを $\|\cdot\|_{i}$ で表すものとし, 定数 $K_{1}$ を $K_{1}=\sup _{\theta \in[0, h]}\left\|e^{A \theta}\right\|_{i}$ により定める.このとき, $z \in U$ より\| $\left\|z_{1}\right\| \leq 1$ であるので, 


$$
\left\|e^{A \theta} R z_{1}\right\| \leq\left\|e^{A \theta} R\right\|_{i}\left\|z_{1}\right\| \leq K_{1}\|R\|_{i}
$$

となる。また $e^{-A \xi} B$ の第 $i$ 行を $h_{i}(\xi)$ で表すとし, 定数 $K_{2}$ を $K_{2}=\max _{i} \sup _{\xi \in[0, h]}\left\|h_{i}(\xi)\right\|$ によって定めるなら ば, Schwarzの不等式および $z \in U$ より $\left\|z_{2}(\cdot)\right\|_{\mathbf{L}^{2}[0, h]} \leq 1$ であることから次式が成り立つ.

$$
\begin{aligned}
& \left\|\int_{0}^{\theta} e^{-A \xi} B z_{2}(\xi) d \xi\right\|^{2}=\sum_{i=1}^{n}\left|\int_{0}^{\theta} h_{i}(\xi) z_{2}(\xi) d \xi\right|^{2} \\
& \leq \sum_{i=1}^{n} \int_{0}^{\theta}\left\|h_{i}(\xi)\right\|^{2} d \xi \int_{0}^{\theta}\left\|z_{2}(\xi)\right\|^{2} d \xi \leq n K_{2}^{2} h
\end{aligned}
$$

したがって, $\forall \theta \in[0, h], \forall z \in U$ に対して

$$
\left\|\int_{0}^{\theta} e^{A(\theta-\xi)} B z_{2}(\xi) d \xi\right\| \leq K_{1} K_{2} \sqrt{n h}
$$

を得る。よって (8), (9) 式から

$$
\left\|\phi_{z}(\theta)\right\| \leq K_{1}\left(\|R\|_{i}+K_{2} \sqrt{n h}\right)
$$

すなわち (5) 式がいえた。

(b) 一般性を失うことなく, $\theta_{1} \leq \theta_{2}$ と仮定できる。こ こで $\Delta \theta=\theta_{2}-\theta_{1} \geq 0$ とすると，

$$
\begin{aligned}
\phi_{z}\left(\theta_{2}\right)-\phi_{z}\left(\theta_{1}\right) & =\left(e^{A \Delta \theta}-I\right) \phi_{z}\left(\theta_{1}\right) \\
+ & e^{A\left(\theta_{1}+\Delta \theta\right)} \int_{\theta_{1}}^{\theta_{1}+\Delta \theta} e^{-A \xi} B z_{2}(\xi) d \xi
\end{aligned}
$$

となる. 右辺第 1 項の $\left(e^{A \Delta \theta}-I\right)$ を除く部分については, そのノルムの上界が $(10)$ 式で与えられる. 第 2 項につい ても同様にして，そのノルムの上界を

$$
\left\|e^{A\left(\theta_{1}+\Delta \theta\right)} \int_{\theta_{1}}^{\theta_{1}+\Delta \theta} e^{-A \xi} B z_{2}(\xi) d \xi\right\| \leq K_{1} K_{2} \sqrt{n \Delta \theta}
$$

と見積もることができる．以上から

$$
\begin{aligned}
& \left\|\phi_{z}\left(\theta_{2}\right)-\phi_{z}\left(\theta_{1}\right)\right\| \\
& \leq\left\|e^{A \Delta \theta}-I\right\|_{i} K_{1}\left(\|R\|_{i}+K_{2} \sqrt{n h}\right)+K_{1} K_{2} \sqrt{n \Delta \theta}
\end{aligned}
$$

が得られる.ここで $g_{1}(\zeta):=\left\|e^{A \zeta}-I\right\|_{i}, g_{2}(\zeta):=\sqrt{n \zeta}$ と する. 各 $j$ に対して $g_{j}(\zeta)$ は $g_{j}(0)=0$ なる連続関数であ るから $\forall \epsilon_{j}>0$ に対して, $\forall \zeta \in\left[0, \delta_{j}\right]$ に対して $\left|g_{j}(\zeta)\right|<\epsilon_{j}$ となるような $\delta_{j}>0$ が存在する。したがって

$$
\epsilon_{1}=\frac{\epsilon}{2 K_{1}\left(\|R\|_{i}+K_{2} \sqrt{n h}\right)}, \epsilon_{2}=\frac{\epsilon}{2 K_{1} K_{2}}
$$

$\underline{\delta}=\min \left(\delta_{1}, \delta_{2}\right)$ とすれば, $\left|\theta_{2}-\theta_{1}\right|<\underline{\delta}$ なる任意の $\theta_{1}, \theta_{2} \in$ $[0, h]$ と $\forall z \in U$ に対して，(6)式が成り立つ.

以下では，作用素 $\mathcal{F}$ のスペクトルを出力の階段関数 近似によって計算することを考える。区間 $[0, h]$ を $N$ 等分し, 周期 $\tau=h / N$ で動作する理想サンプリング 作用素 $\mathcal{S}_{N}$ と零次ホールド作用素 $\mathcal{H}_{N}$ を用いて, 信号 $z_{2}(\cdot) \in\left\{L^{2}[0, h]\right\}^{n}$ をべクトル值の区分的定数関数に変 換する.

$$
\begin{aligned}
& \mathcal{S}_{N} y:=\left[\begin{array}{llll}
y^{*}(0) & y^{*}(\tau) & \cdots & y^{*}((N-1) \tau)
\end{array}\right]^{*} \\
& \mathcal{H}_{N}:\left[\begin{array}{llll}
w^{*}(0) & w^{*}(\tau) & \cdots & w^{*}((N-1) \tau)
\end{array}\right]^{*} \mapsto w(t) \\
& w(t)=w((\ell-1) \tau), \quad t \in[(\ell-1) \tau, \ell \tau]
\end{aligned}
$$

これによって $\mathcal{F} の$ 行列近似を求め, その固有值から $\mathcal{F} の$ スペクトルを計算する。この手続きは以下の定理によっ て正当化される。

\section{【定理 4】いま，}

$$
W=e^{A \tau}, \quad V=\int_{0}^{\tau} e^{A(\tau-\xi)} B d \xi
$$

とする。このとき，行列 $\mathcal{F}_{N}$ を以下のように定める:

$$
\mathcal{F}_{N}:=\left[\begin{array}{ccccc}
P W^{N} R & P W^{N-1} V & \cdots & \cdots & P V \\
R & 0 & \cdots & \cdots & 0 \\
W R & V & \ddots & & \vdots \\
\vdots & \vdots & \ddots & \ddots & \vdots \\
W^{N-1} R & W^{N-2} V & \cdots & V & 0
\end{array}\right]
$$

任意の実数 $\gamma>0$ に対して $\bar{D}_{\gamma}:=\{s \in \mathbf{C} ;|s|>\gamma\}$ とする. $N \rightarrow \infty$ のとき, $\bar{D}_{\gamma}$ 内の $\mathcal{F}_{N}$ の固有值は, $\bar{D}_{\gamma}$ 内の $\mathcal{F}$ の 各固有值に漸近する。

（証明）まず $\mathcal{F} \in \mathcal{B}(\mathcal{Z})$ をいう。いま $(1),(3)$ 式より

$$
\left[\begin{array}{ll}
\mathcal{F}_{11} & \mathcal{F}_{12}
\end{array}\right] z=P \phi_{z}(h)
$$

であるから，(2)式より

$$
\|\mathcal{F} z\|^{2}=\left\|P \phi_{z}(h)\right\|^{2}+\left\|\phi_{z}(\cdot)\right\|_{\mathbf{L}^{2}[0, h]}^{2}
$$

と表される。補題 $\mathbf{1}(\mathrm{a})$ より，任意の $z \in U$ に対して

$$
\begin{aligned}
& \left\|P \phi_{z}(h)\right\|^{2} \leq\|P\|_{i}^{2} K^{2} \\
& \left\|\phi_{z}(\cdot)\right\|_{\mathbf{L}^{2}[0, h]}^{2}=\int_{0}^{h}\left\|\phi_{z}(\theta)\right\|^{2} d \theta \leq K^{2} h
\end{aligned}
$$

が成り立つので,

$$
\|\mathcal{F}\|=\sup _{z \in U}\|\mathcal{F} z\| \leq K \sqrt{\|P\|_{i}^{2}+h}
$$

よって, $\mathcal{F} \in \mathcal{B}(\mathcal{Z})$ である.

作用素 $\mathcal{F}$ の出力の $z_{2}(\cdot)$ 部分を, $\mathcal{H}_{N} \mathcal{S}_{N}$ によって区間 幅 $h / N$ の階段関数に変換したものを $\tilde{\mathcal{F}}_{N}$ とする。 いま,

$$
\tilde{\mathcal{H}}_{N}=\left[\begin{array}{cc}
\mathcal{I} & 0 \\
0 & \mathcal{H}_{N}
\end{array}\right], \quad \tilde{\mathcal{S}}_{N}=\left[\begin{array}{cc}
\mathcal{I} & 0 \\
0 & \mathcal{S}_{N}
\end{array}\right]
$$

とすると，具体的に

$$
\tilde{\mathcal{F}}_{N}=\tilde{\mathcal{H}}_{N} \tilde{\mathcal{S}}_{N} \mathcal{F}
$$

である. 先と同様に

$$
\left\|\tilde{\mathcal{F}}_{N} z\right\|^{2}=\left\|P \phi_{z}(h)\right\|^{2}+\left\|\mathcal{H}_{N} \mathcal{S}_{N} \phi_{z}(\cdot)\right\|_{\mathbf{L}^{2}[0, h]}^{2}
$$


である．実数 $x$ に対して $x$ を超えない最大の整数を $\lfloor x\rfloor$ で表そう。このとき，

$$
\mathcal{H}_{N} \mathcal{S}_{N} \phi_{z}(\theta)=\phi_{z}(\tau\lfloor\theta / \tau\rfloor)=: \phi_{z}(\eta(\theta))
$$

と書き表すことができる.ここで $\forall \theta \in[0, h]$ に対して $\eta(\theta) \in[0, h]$ であるから, 補題 $\mathbf{1}(\mathrm{a})$ より (14) 式の右辺第 2 項の上界は

$$
\begin{aligned}
\left\|\mathcal{H}_{N} \mathcal{S}_{N} \phi_{z}(\cdot)\right\|_{\mathbf{L}^{2}[0, h]}^{2} & =\int_{0}^{h}\left\|\phi_{z}(\eta(\theta))\right\|^{2} d \theta \\
& \leq K^{2} h
\end{aligned}
$$

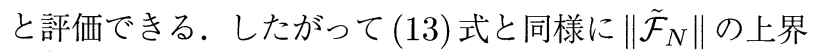
を見積もることができるから $\tilde{\mathcal{F}}_{N} \in \mathcal{B}(\mathcal{Z})$ である。いま $\mathcal{F}$ と $\tilde{\mathcal{F}}_{N}$ の差を $\mathcal{F}$ に対する摂動とみなし, これを $\Delta_{N}$ とおく.すなわち

$$
\tilde{\mathcal{F}}_{N}=\mathcal{F}+\Delta_{N}
$$

とする. いま $\mathcal{F}, \mathcal{F}_{N} \in \mathcal{B}(\mathcal{Z})$ であることが示されたので, 定理 3 より generalized sense において $\mathcal{F}_{N} \rightarrow \mathcal{F}$ となる ためには $\left\|\Delta_{N}\right\| \rightarrow 0$ であればよい。具体的には，(2), (15) 式より摂動の大きさは次のように表される。

$$
\begin{aligned}
\left\|\Delta_{N}\right\| & =\sup _{z \in U}\left\|\left(\mathcal{H}_{N} \mathcal{S}_{N}-\mathcal{I}\right)\left[\mathcal{F}_{21} \mathcal{F}_{22}\right] z\right\|_{\mathbf{L}^{2}[0, h]} \\
& =\sup _{z \in U}\left[\int_{0}^{h}\left\|\left(\mathcal{H}_{N} \mathcal{S}_{N}-\mathcal{I}\right) \phi_{z}(\theta)\right\|^{2} d \theta\right]^{1 / 2}
\end{aligned}
$$

補題 $\mathbf{1}(\mathrm{b})$ から, 任意の正数 $\epsilon_{1}$ に対して $\epsilon=\epsilon_{1} / \sqrt{h}$ とす ると, $\forall z \in U,\left|\theta_{1}-\theta_{2}\right|<\delta$ なる $\forall \theta_{1}, \theta_{2} \in[0, h]$ について (6) 式が成立するような $\delta$ が存在する. 先と同様, 記号 $\lfloor\cdot\rfloor$ を用いて $\eta(\theta)=\tau\lfloor\theta / \tau\rfloor$ とおけば

$$
\left(\mathcal{H}_{N} \mathcal{S}_{N}-\mathcal{I}\right) \phi_{z}(\theta)=\phi_{z}(\eta(\theta))-\phi_{z}(\theta)
$$

であり, $|\eta(\theta)-\theta|<\tau=h / N$ である.したがって $N>h / \delta$ とすれば， (17) 式より $\forall z \in U, \forall \theta \in[0, h]$ に対して

$$
\left\|\left(\mathcal{H}_{N} \mathcal{S}_{N}-\mathcal{I}\right) \phi_{z}(\theta)\right\|<\epsilon_{1} / \sqrt{h}
$$

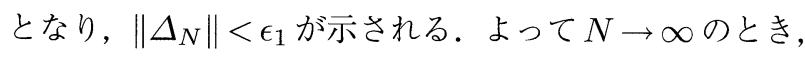
$\left\|\Delta_{N}\right\| \rightarrow 0$, すなわち摂動 $\Delta_{N}$ は generalized senseにお いて収束する. したがって定理 $\mathbf{2}$ から $\bar{D}_{\gamma}$ 内の $\mathcal{F}$ の有限 固有值系の, 摂動 $\Delta_{N}$ に対する変化は連続である. 作用 素の順序変更を施して

$$
\mathcal{F}_{N}=\tilde{\mathcal{S}}_{N} \mathcal{F} \tilde{\mathcal{H}}_{N}
$$

とすると $\mathcal{F}_{N}: \mathbf{R}^{N n} \rightarrow \mathbf{R}^{N n}$ であり，具体的な計算（付 録参照）により，行列表現 (12) 式が得られる。作用素 $\tilde{\mathcal{F}}_{N}$ と $\mathcal{F}_{N}$ の非零の固有值は一致するから, 題意が成り 立つ.

補題 1(a), (b) で示していることは関数族 $\Phi_{U}=\left\{\phi_{z} \mid z \in\right.$ $U\}$ の一様有界性ならびに同程度一様連続性にほかなら

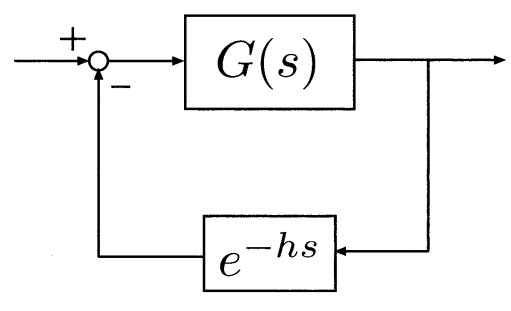

Fig. 1 Retarded delay-differential system

ない [9]. 実際, 文献 [12] では, サンプル值系の周波数 応答の数值計算に関連して, ある関数族の一様有界性と 同程度一様連続性から $C[a, b]$ に対する相対コンパクト性 をいい (Arzelàの定理)，これを任意の精度で矩形近似 できることの根拠としている，近似可能であることを具 体的に示すには, $C[a, b]$ に対する相対コンパクト性が全 有界性と同值であることを用いて, 関数族が有限個の連 続関数の集合で $\epsilon$-被覆可能であることをいい, この有限 個の連続関数を階段関数近似する場合の最悪ケースを論 じればよい.しかしながら，関数族に関するいくつかの 概念を経由する必要があることから, 必ずしも直接的な 証明とはいえない.ここでは補題 1 の性質は用いるもの の, 関数族の概念は陽に用いずに，より初等的な議論か ら証明を与えている。

\section{4. 数值例}

Fig. 1のブロック線図で表される系の安定性を考える. いま $G(s)$ を有理伝達関数 $2 /(2 s+1)$ とすると, 対応す る閉ループ系の状態方程式は

$$
\dot{x}(t)=-1 / 2 x(t)-x(t-h)
$$

となる ${ }^{1}$. 文献 $[5,6]$ で示されているように, 微分差分系 (18) 式の安定性は, $A=-1 / 2, B=-1, P=R=1$ とし た作用素 $\mathcal{F}$ のスペクトル半径によって定まる．前向き 要素 $G(s)$ のゲイン交叉周波数 $\omega_{0}=\sqrt{3} / 2$ における位相 が $\angle G\left(j \omega_{0}\right)=-\pi / 3$ であことから, 閉ループ系はむだ 時間長 $h \in[0,4 \sqrt{3} \pi / 9]$ に対して安定である。安定限界 $h=4 \sqrt{3} \pi / 9$ における作用素 $\mathcal{F}$ の固有值を行列近似 $\mathcal{F}_{N}$ から求める。この手続きによって $N \rightarrow \infty$ とき真值が 得られることは定理 4 により保証されている. 分割数 $N$ に対する $\mathcal{F}_{N}$ の固有值 (絶対值の大きい方から 6 個) の変 化を Table 1 に示す. 作用素 $\mathcal{F}$ の固有值の真值は, (18) 式の特性根 $s_{0}$ を求めて $\lambda_{0}=e^{h s_{0}}$ とすることにより, あ るいは別途, 特性方程式に等価なある超越方程式の根を 収束計算することで求められる $[6]$. 分割数 $N$ の増加に ともない, 行列 $\mathcal{F}_{N}$ の固有值が $\mathcal{F}$ の固有值に近づくこと が確認できる. しかしながら, 分割数 $N$ の増加に対する 真值への収束速度はかなり緩やかであり, 定理 4 で述べ

\footnotetext{
1 この例は，詳細な証明を含まない著者らの解説記事 $[6]$ でも扱っているが，本論文の主結果に基づく具体的な 計算例として再掲する.
} 
Table 1 Eigenvalues of $\mathcal{F}_{N}$

\begin{tabular}{|c|c|c|}
\hline & $z_{1}, z_{2}$ & $z_{3}, z_{4}$ \\
\hline$N=100$ & $-0.494 \pm 0.872 j$ & $0.011 \pm 0.311 j$ \\
$N=200$ & $-0.497 \pm 0.869 j$ & $0.005 \pm 0.309 j$ \\
$N=400$ & $-0.499 \pm 0.868 j$ & $0.002 \pm 0.309 j$ \\
$N=800$ & $-0.499 \pm 0.867 j$ & $0.000 \pm 0.308 j$ \\
$N=1600$ & $-0.500 \pm 0.866 j$ & $-0.001 \pm 0.308 j$ \\
true value & $-1 / 2 \pm \sqrt{3} / 2 j$ & $-0.001 \pm 0.308 j$ \\
\hline \hline & $z_{5}, z_{6}$ & $z_{7}, z_{8}, \ldots$ \\
\hline$N=100$ & $0.019 \pm 0.173 j$ & $\ldots$ \\
$N=200$ & $0.013 \pm 0.172 j$ & $\ldots$ \\
$N=400$ & $0.010 \pm 0.172 j$ & $\ldots$ \\
$N=800$ & $0.008 \pm 0.172 j$ & $\ldots$ \\
$N=1600$ & $0.008 \pm 0.171 j$ & $\ldots$ \\
true value & $0.007 \pm 0.171 j$ & $\ldots$ \\
\hline
\end{tabular}

た計算法は決して計算効率に優れたものではない. 前述 のとおり作用素 $\mathcal{F}$ の固有值はある超越方程式の根として 特徴づけられているので $[4,5]$, 各種の応用例に対する実 際の計算では適当な $N$ を用いて各固有值近傍の初期值 を求め, これらの初期值から収束計算によって真值を探 索している.このときの $\mathcal{F}$ のスペクトルの分布を Fig. 2 に示す．単位円周上の固有值が確認できる.

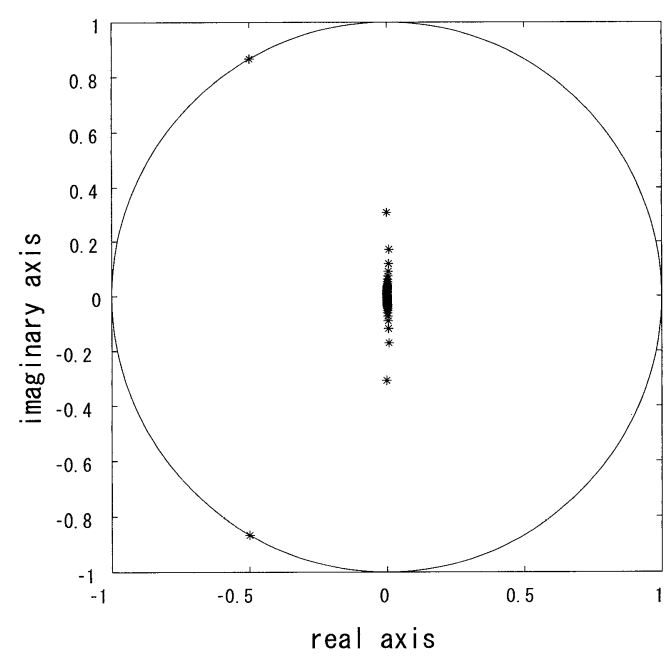

Fig. 2 Distribution of the spectra of $\mathcal{F}$

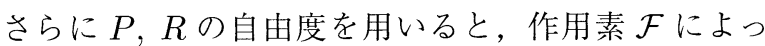
て遅延フィードバック制御下にある状態にジャンプを有 する線形システムの安定性を記述できる。文献 [4]では Garciaらの compass walker モデル, 文献 [7] では大須 賀，杉本らの脚ロボット Quartet-III について，本論文 の結果を根拠とした解析をおこなっている。

\section{5. おわりに}

あるクラスのたたみ込み積分作用素のスペクトルの数 値計算に関して，近似行列の固有值計算による手続きの
数学的正当性を簡潔に示した. 具体的には出力の階段関 数近似による摂動に対して，スペクトルが連続になるた めの諸条件を，本論文で考えている作用素 $\mathcal{F} か ゙$ 満たして いることを証明した。 得られた近似公式は理論的な収束 性は保証されているものの, 計算効率に優れたものでは ないので, 実用上は非線形方程式の根の局所探索法と組 み合わせて利用するなどの工夫が必要である.

\section{謝辞}

本論文の主結果の証明の簡単化に関して有益な助言を いただいた査読者の方々に感謝します。

\section{参考文献}

[1] B. Bamieh and J. B. Pearson: A general framework for linear periodic systems with applications to $H_{\infty}$ sampled-data control; IEEE TAC, Vol. 37, pp. 418-435 (1991)

[2] G. Dullerud: Computing the $L_{2}$-induced norm of a compression operator; Systems $\&$ Control Letters, Vol. 37, pp. 87-91 (1999)

[3] 藤田, 黒田, 伊藤 : 関数解析, 岩波基礎数学選書, 岩波 書店 (1991)

[4] 平田, 小亀：状態にジャンプを有する線形システムの遅 延フィードバック制御；システム制御情報学会論文誌， Vol. 18, No. 3, pp. 118-125 (2005)

[5] K. Hirata and H. Kokame: Stability analysis of retarded systems via lifting technique; Proc. of CDC2003, CD-ROM (2003)

[6] 平田, 小亀：むだ時間系の安定解析再訪 -受動歩行の遅 延フィードバック制御まで- (1) ; 計測と制御, Vol. 45, No. 3, pp. 260-266 (2006)

[7] 平田, 大須賀, 杉本：むだ時間系の安定解析再訪 -受動 歩行の遅延フィードバック制御まで- $(2)$; 計測と制御, Vol. 45, No. 4, pp. 376-380 (2006)

[8] T. Kato: Perturbation Theory for Linear Operators, Spriger (1980)

[9] コルモゴロフ，フォミーン：関数解析の基礎，原書第 4 版, 岩波書店 (1979)

[10] T. A. Lypchuk, M. C. Smith and A. Tannenbaum: Weighted sensitivity minimization: general plant in $H^{\infty}$ and rational weights; Linear Algebra Appl., Vol. 109, pp. 71-90 (1988)

[11] Y. Yamamoto, K. Hirata and A. Tannenbaum: Some remarks on Hamiltonians and the infinitedimensional one block $H^{\infty}$ problem; Systems $\&$ Control Letters, 29, pp. 111-117 (1996)

[12] Y. Yamamoto, A. G. Madievski and B. D. O. Anderson: Approximation of frequency response for sampled-data control systems; Automatica, Vol. 35, pp. 729-734 (1999)

[13] Y. Yamamoto: A function space approach to sampled-data control systems and tracking problem; IEEE TAC, Vol. 39, pp. 703-713 (1994) 
[14] K. Zhou and P. P. Khargonekar: On the weighted sensitivity minimization problem for delay systems; Systems \& Control Letters, Vol. 8, pp. 307-312 (1987)

付 録

\section{$\mathcal{F}_{N}$ の行列表現}

区間 $[0, h]$ の $k$ 番目のサンプル時刻を $\tau_{k}$ とすると， $\tau_{k}=\tau k, k=0, \cdots, N$

となる。作用素 $\mathcal{F}_{N}$ の入出力 $z^{d, i}, z^{d, o} \in \mathbf{R}^{N n}$ を

$$
z^{d, i}=\left[\begin{array}{c}
z_{1}^{d, i} \\
z_{2}^{d, i}(0) \\
\vdots \\
z_{2}^{d, i}(N-1)
\end{array}\right], \quad z^{d, o}=\left[\begin{array}{c}
z_{1}^{d, o} \\
z_{2}^{d, o}(0) \\
\vdots \\
z_{2}^{d, o}(N-1)
\end{array}\right]
$$

とし，F対する入出力を

$$
z^{i}=\left[\begin{array}{c}
z_{1}^{i} \\
z_{2}^{i}(\theta)
\end{array}\right], \quad z^{o}=\left[\begin{array}{c}
z_{1}^{o} \\
z_{2}^{o}(\theta)
\end{array}\right]
$$

とする. 入力側の零次ホールド $\tilde{\mathcal{H}}_{N}$ によって

$$
\left\{\begin{array}{l}
z_{1}^{i}=z_{1}^{d, i} \\
z_{2}^{i}(\theta)=z_{2}^{d, i}(k), \theta \in\left[\tau_{k}, \tau_{k+1}\right], k=0, \cdots, N-1
\end{array}\right.
$$

という対応づけがなされ，同様に出力側のサンプラ $\tilde{\mathcal{S}}_{N}$ によって

$$
\left\{\begin{array}{l}
z_{1}^{d, o}=z_{1}^{o} \\
z_{2}^{d, o}(k)=z_{2}^{o}\left(\tau_{k}\right), k=0, \cdots, N-1
\end{array}\right.
$$

という対応づけがなされる。いま $\mathcal{F}$ の作用から

$$
z_{2}^{o}\left(\tau_{k}\right)=e^{A \tau_{k}} R z_{1}^{i}+\int_{0}^{\tau_{k}} e^{A\left(\tau_{k}-\xi\right)} B z_{2}^{i}(\xi) d \xi
$$

となる.ここで (11) 式の記号を用いれば，第 1 項は $W^{k} R z_{1}^{i}$ である. 第 2 項は $k=0$ のとき $0, k \geq 1$ のとき

$$
\begin{aligned}
& \int_{0}^{\tau_{k}} e^{A\left(\tau_{k}-\xi\right)} B z_{2}^{i}(\xi) d \xi \\
& =\sum_{j=0}^{k-1} \int_{\tau_{j}}^{\tau_{j+1}} e^{A\left(\tau_{k}-\xi\right)} B z_{2}^{i}(\xi) d \xi=: \sum_{j=0}^{k-1} \alpha_{k, j} z_{2}^{d, i}(j)
\end{aligned}
$$

とおくと

$$
\alpha_{k, j}=e^{A \tau_{k-j}} \int_{0}^{\tau} e^{-A \zeta} B d \zeta=W^{k-j-1} V
$$

である。また

$$
z_{1}^{o}=P z_{2}^{o}\left(\tau_{N}\right)
$$

であるから，以上をまとめると

$$
z^{d, o}=\left[\begin{array}{ccccc}
P W^{N} R & P W^{N-1} V & \cdots & \cdots & P V \\
R & 0 & \cdots & \cdots & 0 \\
W R & V & \ddots & & \vdots \\
\vdots & \vdots & \ddots & \ddots & \vdots \\
W^{N-1} R & W^{N-2} V & \cdots & V & 0
\end{array}\right] z^{d, i}
$$

を得る。 